\title{
Epistaxis management with hilotherapy: a pilot study*
}

H. Saeed"\#, E. Heward²\#, M. Khan' , C. Lynch², S. Khwaja²

' ENT Department, Manchester University NHS Foundation Trust, Wythenshawe Hospital, M23 9LT Manchester, UK

ENT Department, Stockport NHS Foundation Trust, Stockport SK2 7JE, UK
Rhinology Online, Vol 3: 45 - 49, 2020

http://doi.org/10.4193/RHINOL/20.002

*Received for publication:

January 13, 2020

Accepted: February 24, 2020

Published: May 11, 2020

\# These authors contributed equally and

are joint first author

\begin{abstract}
Background: Hilotherm contoured masks provide facial cooling to produce local vasoconstriction without many of the risks of cryotherapy.
\end{abstract}

Methodology: This pilot study investigates the feasibility of hilotherapy in managing acute epistaxis.

Results: Thirteen patients were recruited over 11 months at two hospitals in the North West of England. All patients received conventional initial epistaxis management simultaneously. Five patients had complete cessation and 6 had a reduction in epistaxis during the initial 20 minutes of hilotherapy. No adverse affects were recorded in the pilot cohort during hilotherapy. A post therapy questionnaire showed that patients found the mask easy to fit, secure and comfortable to wear.

Conclusions: Hilotherapy has demonstrated positive outcomes in terms of patient satisfaction and safety in this small pilot population. Further randomised controlled studies are now required to investigate if hilotherapy is effective in the management of acute epistaxis.

Key words: epistaxis, hilotherapy, hilotherm, nose

\section{Introduction}

Epistaxis is the most frequent acute ENT presentation to secondary care, despite this there is sparsity of evidence supporting emergency management ${ }^{(1)}$. Although nasal cautery and nasal packing are the mainstay of management for persistent epistaxis, additional interventions, such as ice packs, are used occasionally ${ }^{(1)}$. Limited evidence suggests that intra-oral ice packs reduce intra-nasal blood flow which could explain its role in epistaxis management ${ }^{(2)}$. However, external ice application has not been shown to be effective ${ }^{(3)}$. Hilotherm masks are contoured cooling face masks which have been shown to reduce post operative pain and swelling following maxillofacial surgery and are well tolerated by patients ${ }^{(4)}$.

The objective of the pilot study was to assess the tolerability and safety of using the Hilotherm mask in the first line management of epistaxis in the Accident and Emergency setting.

\section{Materials and Methods}

A prospective pilot study was undertaken at two hospitals in the North West of England between April 2018 to February 2019 following ethical approval. Investigators were ENT doctors trained to apply the Hilotherm mask, consent patients and collect data.

\section{Protocol}

Patients who had ongoing epistaxis and met the inclusion criteria where enrolled in the pilot study (Table 1). Bleeding severity was not recorded. All patient enrolled were clinically stable with active epistaxis. Patients who were unstable or were ineligible 
Table 1. Inclusion criteria for pilot study.

\section{Inclusion criteria}

Patients 18 years or older presenting with a nose bleed

no signs of systemic shock secondary to bleeding (severe blood loss) * no confusion

no lack of capacity (able to make clear decisions)

no lacerations underneath the area the mask covers.

*signs of systemic shock were classified as heart rate $>100$, blood pressure systolic $<100$ or $>180$ or raised respiratory rate, confusion.

Table 2. Post Hilotherapy Questionnaire.

1. The Hilotherm mask felt easy to fit;

2. Once applied to the face, the Hilotherm mask felt secure and in place;

3. The Hilotherm mask felt comfortable to wear;

4. I felt the Hilotherm mask reduced the amount my nose was bleeding

5. The Hilotherm mask caused me discomfort/ felt stressful to wear

\section{I felt the Hilotherm mask was kept on for too long}

7. If I had a nose bleed again, I would wear the Hilotherm mask again to help

Answer Key: 1 - Strongly Agree, 2 - Agree, 3 - Neutral, 4 - Disagree, 5 Strongly Disagree.

were not referred to the recruiting doctors by A\&E triage. The Hilotherm machine was set at 10 degrees centigrade and connected to a single use face mask (Figure 1). Following informed consent the Hilotherm mask was fitted for an initial period of 20 minutes. If the bleeding had improved or stopped following 20 minutes of treatment the Hilotherm mask remained fitted for a 20 further minutes (Figure 2). A subjective decision was made by the supervising doctor and the patient to whether the flow of epistaxis had improved after the initial 20 minutes of hilotherapy.

The mask was removed if there was no improvement after the initial 20 minutes of hilotherapy, 40 minutes of total hilotherapy treatment, patient preference, worsening observations or profuse bleeding. Patients' received conventional epistaxis management simultaneously, this involved continued nasal pressure application during hilotherapy. Following hilotherapy if epistaxis continued then either nasal cauterisation or packing was performed. Cessation of epistaxis was determined at the time of packing if bleeding had ceased. Bleeding time was accurately assessed by the recruiting doctor from the time of hilotherm

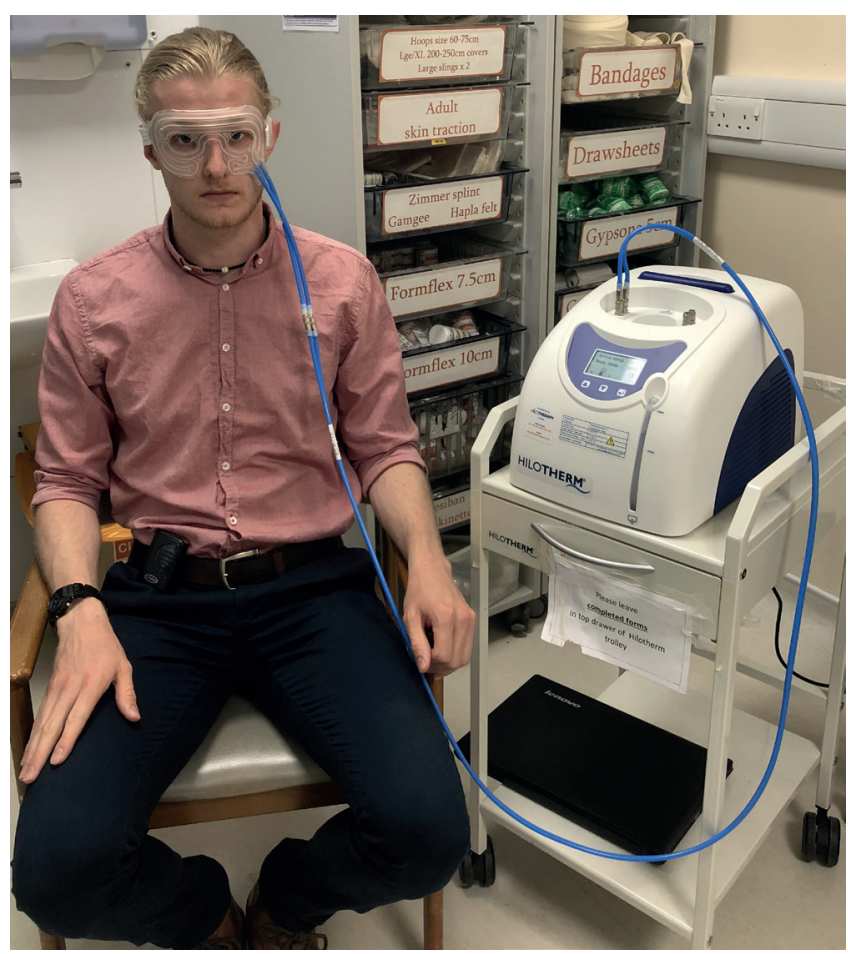

Figure 1. Hilotherm mask setup.

mask application to the time of complete epistaxis cessation. All of the patients were treated in the sitting position.

Patients were free to withdraw from the trial at any time and no further data was analysed from the individual. Clinicians recorded anticoagulant and antiplatelet use, duration of bleeding and patient demographics. All patients completed a questionnaire following their hilotherapy treatment independently (Table 2).

\section{Results}

A total of 14 patients were recruited with active epistaxis. The data collection was incomplete for 1 patient, therefore they were excluded from the data analysis. The median patient age at presentation was 76 years. Of the 13 patients 5 had complete cessation and 6 reduction in bleeding during the first 20 minutes of hilotherapy. Median time to epistaxis cessation was 37.5 minutes (range 5-85 minutes). Five of the patients were taking an antiplatelet, 2 novel oral anticoagulant (NOAC) and 1 Low Molecular Weight Heparin. Of these 3 patients required nasal packing and 1 patient nasal cauterisation. All 3 patients who received nasal packing were admitted. No adverse affects, patient deterioration or worsening of epistaxis were recorded in the cohort during hilotherapy treatment.

All 13 patients provided questionnaire feedback following hilotherapy (Figure 3). The majority of participants felt the mask easy to fit, secure, comfortable and would wear in the future. 


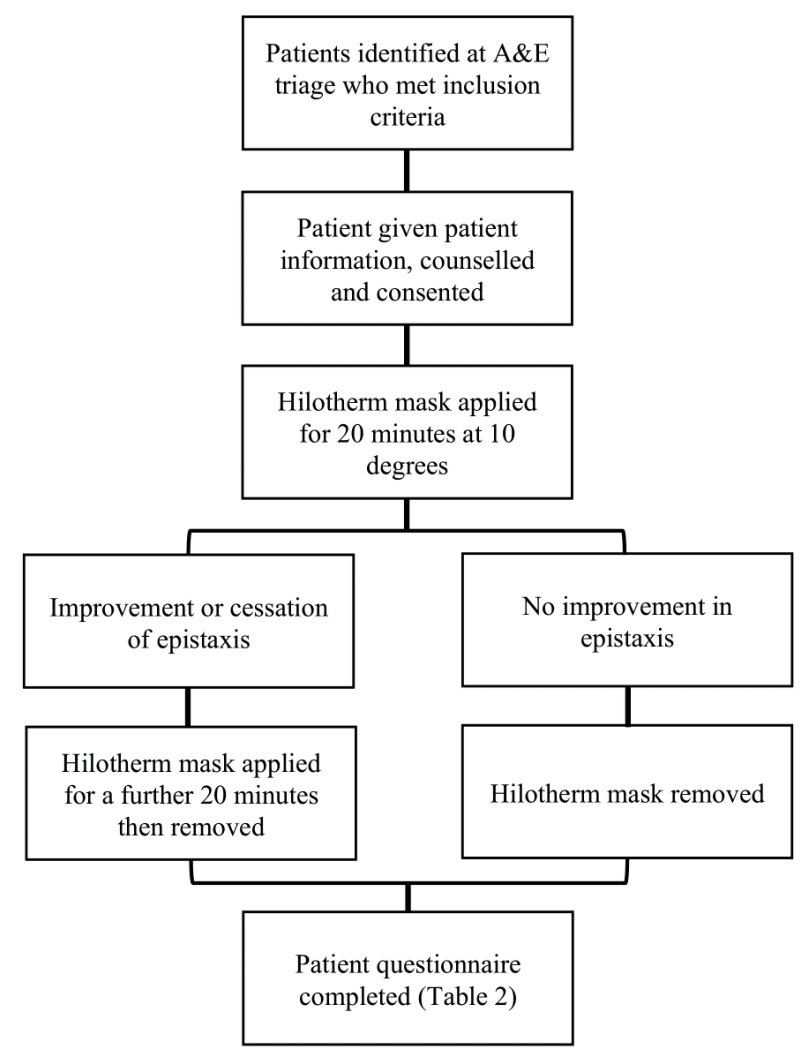

Figure 2. Pilot study flowchart.

Overall there was no consensus whether the mask helped with their epistaxis. In addition, participants didn't feel the duration of hilotherapy was too long. No patients withdrew from the study while receiving hilotherapy.

\section{Discussion}

There is currently insufficient evidence in the literature addressing the management of acute epistaxis. Intra-oral ice packs have been shown to reduce nasal blood flow which is thought could reduce epistaxis severity in clinical practice ${ }^{(5)}$. Hilotherm masks now offer a standardised application device that provides controlled external facial cooling, replacing the need for ice pack application. Standardised application makes it possible to investigate the use of external ice packs in managing acute epistaxis. Previous studies investigating the physiological changes following ice pack application examined young and healthy participants which is not representative of the patient population who present with epistaxis ${ }^{(2,3)}$. The multicenter national epistaxis audit demonstrated the median age of those admitted with epistaxis was 73 years and the majority were co-morbid ${ }^{(1)}$. Porter et. al. demonstrated that application of intraoral ice packs for a period of 3 seconds significantly reduced nasal mucosal blood flow compared to control. Ice packs applied externally to the forehead showed no difference compared with control ${ }^{(2)}$. Teymoortash et. al. also demonstrated no significant change to either nasal mucosal blood flow or nasal airflow following external ice pack application to the neck for 5 minutes ${ }^{(3)}$. Current physiological literature therefore shows mixed results supporting ice pack use in managing epistaxis. There are currently no published studies investigating the clinical outcome of ice pack use in epistaxis.

Multiple patient and haematological factors affect the severity of epistaxis and time taken for bleeding cessation ${ }^{(1,6)}$. Eight of the patients in our cohort were receiving antiplatelet, anticoagulant or low molecular weight heparin which are known to increase epistaxis frequency and severity ${ }^{(7)}$. Our small cohort

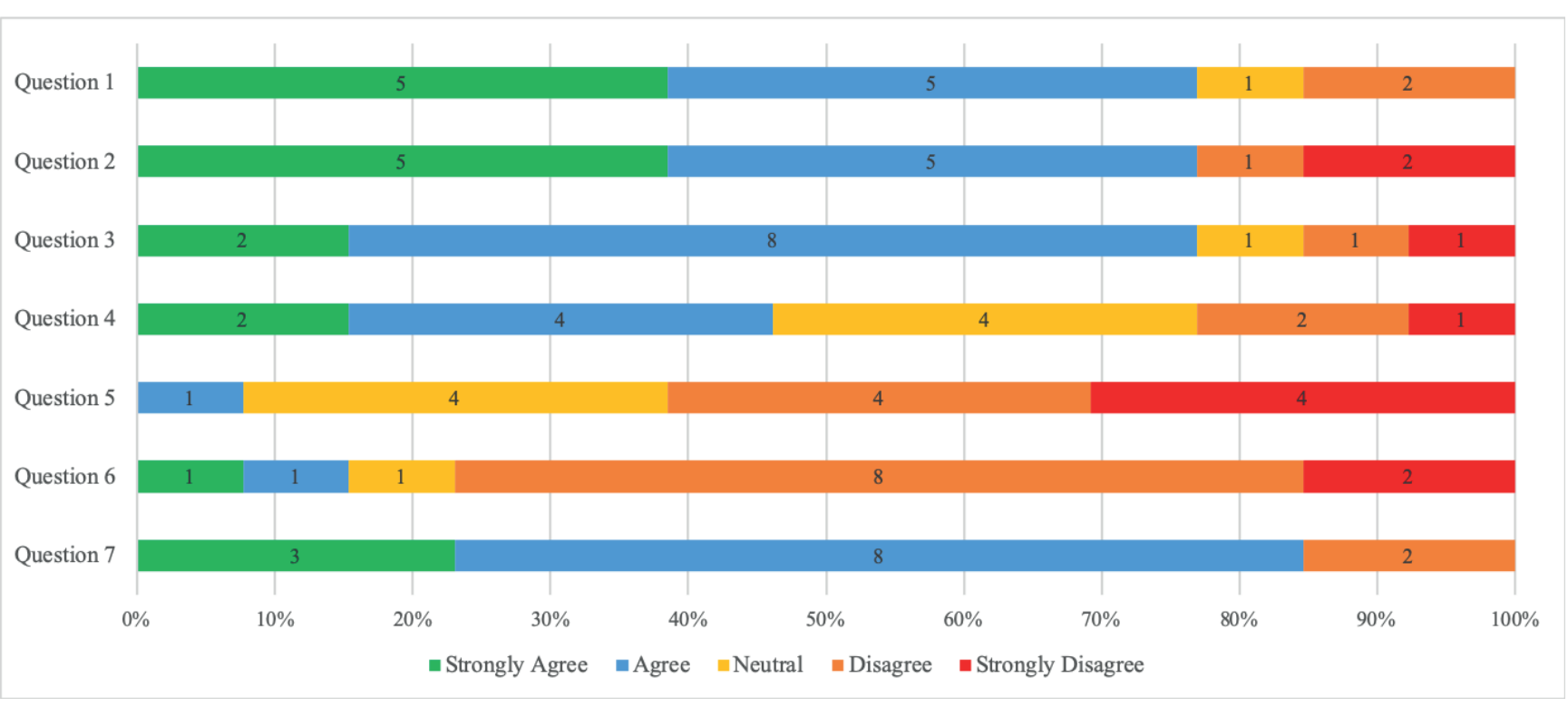

Figure 3. Post hilotherapy questionnaire results. 
of patients undergoing hilotherapy had a median time to haemostasis of 37.5 minutes. In this small population we are unable to address the efficacy of hilotherapy in managing acute epistaxis. There are many factors which could have attributed to this reduction in bleeding cessation time. Patients were seen on presentation to the emergency department directly by the ENT team and patients with profuse bleeding were excluded from the study. In addition, patients recruited were under close observation by ENT doctors during hilotherapy treatment and bleeding cessation was classified when successful nasal cautery or packing was performed. Due to the small numbers and heterogenous population it is currently not possible to identify whether hilotherapy reduces acute epistaxis. Reassuringly no patients developed worsening epistaxis or deterioration while on hilotherapy treatment. Reattendances with epistaxis were not recorded. Future studies which examine the effectiveness of hilotherapy in managing acute epistaxis should also assess epistaxis recurrence following therapy.

Hilotherapy provides a controlled facial cooling therapy which overcomes problems encountered with traditional cryotherapy use such as ice burns and local ice storage. The Hilotherm contoured masks are single use and the small machine requires sterile water to deliver the cooling therapy. The Hilotherm machine costs $£ 1,950+$ VAT for 24 months. The machine has no limit on number of uses. Single use open eye masks cost $£ 23.70$ + VAT each. The single use masks are one size. In our experience there were no occasions where the mask size was problematic. It is suggested that at a temperature of 10 degrees the metabolic rate of tissue falls by $50 \%$ and optimal lymphatic drainage occurs which reduces tissue oedema and pain ${ }^{(8)}$. On cold exposure the sympathetic nervous system causes local cutaneous vasoconstriction ${ }^{(9)}$. Hilotherapy avoids the risk of cooling tissue to 0 degrees causing tissue death, oedema and pain.

A limitation identified by investigators was that application and observation of patients receiving hilotherapy is time consuming. Hilotherapy is easy to deliver which may enable the delivery by allied health professionals in the emergency department. Capturing acute patient admissions who have active ongoing epistaxis on arrival to hospital can be challenging because of busy emergency departments, time pressures and that many patients present out of hours. The study team believe these factors resulted in low recruitment numbers to the pilot study. The use of a dedicated research nurse in future studies would help overcome many of these challenges. Currently the cost of delivering and supervising hilotherapy may be prohibitive to its use in the NHS. Future studies need to address its cost-effectiveness in managing acute epistaxis in the hospital setting.
The use of postoperative hilotherapy by maxillofacial surgeons is becoming increasingly popular. A recent systematic review demonstrated that hilotherapy reduced post-operative pain and swelling compared to ice cooling treatments ${ }^{(4)}$. Patient reported satisfaction was higher for hilotherapy compared to other ice cooling treatments ${ }^{(4)}$. Our questionnaire findings also demonstrate positive patient satisfaction when undergoing hilotherapy. Overall feedback was that the masks were easy to apply, felt secure, were comfortable and patients would wear the mask again (Figure 3).

\section{Conclusions}

This pilot study has demonstrated that Hilotherm masks are well tolerated by patients and are safe to use for acute epistaxis. $\mathrm{Hi}$ lotherapy provides an excellent alternative to non-standardised methods of ice therapy in the management of epistaxis. As with many aspects of epistaxis management there is still limited evidence to its effectiveness ${ }^{(1,6)}$. This pilot study has highlighted challenges in patient recruitment which need to be considered in future studies. Future randomised studies are now required to establish the effectiveness of hilotherapy in acute epistaxis.

\section{Authorship contribution}

HS wrote the study protocol, completed the ethics application and edited the manuscript. EH collected data, performed data analysis and drafted the manuscript. MH edited the study protocol and manuscript. CL collected data and edited the manuscript. SK edited the study protocol and manuscript.

\section{Conflict of interest}

The authors have no conflicts of interest to declare.

\section{Ethics approval and consent to participate}

Ethical approval was completed (IRAS No. 230638). All patients provided written informed consent.

\section{Consent for publication}

Authors consent for this material to the published by Rhinology Online.

\section{Availability of data and materials}

The data of the pilot study is available within the manuscript.

\section{Funding}

Hilotherm LTD provided 2 Hilotherm machines to the 2 hospitals for the study period. 


\section{References}

1. INTEGRATE (The National Ent Trainee Research Network). Epistaxis 2016: national audit of management. J Laryngol Otol 2017 131: 1131-1141.

2. Porter M, Marais J, Tolley N. The effect of ice packs on nasal mucosal blood flow. Acta Otolaryngol (Stockh) 1991; 111:1 122-1125.

3. Teymoortash A, Sesterhenn A, Kress R, Sapundzhiev N, Werner JA. Efficacy of ice packs in the management of epistaxis. Clin. Otolaryngol 2003; 28: 545-547.

4. Bates AS, Knepil GJ. Systematic review and meta-analysis of the efficacy of hilotherapy following oral and maxillofacial surgery. Int J Oral Maxillofac Surg 2016; 45: 110-117.

5. Khan M, Conroy K, Ubayasiri K et al. Initial assessment in the management of adult epistaxis: systematic review. J Laryngol Otol 2017; 131: 1035-1055

6. INTEGRATE (The National Ent Trainee Research Network). The British Rhinological Society multidisciplinary consensus recommendations on the hospital management of epistaxis. J Laryngo Otol 2017; 131: 1142-1156.

7. Williams A, Biffen A, Pilkington $\mathrm{N}$ et al. Haematological factors in the management of adult epistaxis: systematic review. J Laryngo Otol 2017; 131: 1093-1107.

8. Hilotherm LTD. How can hilotherapy help? Available from: https://www.hilotherm. co.uk/how-can-hilotherapy-help [Accessed date: 6 January 2020].
9. Charkoudian N. Mechanisms and modifiers of reflex induced cutaneous vasodilation and vasoconstriction in humans. J Appl Physiol 2010; 109: 1221-1228.

\section{Mr Elliot Heward}

ENT Department

Stockport NHS Foundation Trust

Stockport, SK2 7JE

United Kingdom

E-mail: elliotheward@doctors.org.uk

ISSN: 2589-5613 / @2020 The Author(s). This work is licensed under a Creative Commons Attribution 4.0 International License. The images or other third party material in this article are included in the article's Creative Commons license, unless indicated otherwise in the credit line; if the material is not included under the Creative Commons license, users will need to obtain permission from the license holder to reproduce the material. To view a copy of this license, visit http://creativecommons.org/licenses/by/4.0/ 